\title{
Stakeholder collaboration and irrigation practices in Ghana: issues, challenges, and the way forward
}

\author{
Dorothy Julian Nalumu ${ }^{1} \cdot$ Henry Mensah ${ }^{2}$ (I) $\cdot$ Owusu Amponsah ${ }^{3}$ (D) Stephen Appiah Takyi ${ }^{3}$
}

Received: 7 January 2020 / Accepted: 19 February 2021 / Published online: 22 April 2021

(c) The Author(s) 2021 OPEN

\begin{abstract}
In the era of climate change, irrigation is playing a pivotal role in stabilising food production, enabling dry season farming, and improving farmers' livelihoods, particularly in Asia and African countries. Recently, Ghana has taken steps to respond to the concept of stakeholder collaboration to improve the irrigated agricultural sub-sector as well as enhance farmers' resilience to changing climate. However, there is limited attention to recent diverging experiences on collaborative practices from irrigation stakeholders. Using the Weija Irrigation Scheme as a case study, this study explores stakeholders' perceptions of collaborative practices in irrigation management by identifying gaps and providing suggestions to enhance stakeholder collaboration. We conducted focus group discussions with farmers and in-depth interviews with key informants, such as heads of farmer groups, government departments, agencies, and agricultural extension agents. Secondary data from conventional literature, organisational websites, and quarterly reports were also used. Following the integrated collaboration governance theory, effective collaboration was measured based on the tripartite prism of "principled engagement, shared motivation, and capacity for joint action". Analysis of the data reveals that despite the central government's resolve for collaborative irrigation planning and management, effective collaboration remains limited. Based on principle engagement, this study points out that weak communication and sharing of information remain in the planning and management of the Weija Irrigation Scheme. In terms of shared motivation, there were minimal commitment to joint project planning, exclusion of some key stakeholders from meetings, and negative attitudes towards collaboration. Finally, the capacity for joint action (e.g. lack of fund, time, staff, and equipment) is limited. The policy implications and suggestions for further research are presented in the study.
\end{abstract}

Keywords Collaboration challenges · Irrigation stakeholders · Ghana · Irrigated agriculture

\section{Introduction}

Global agriculture is facing serious challenges due to the impact of climate change (for instance, frequent floods, wildfire, heatwaves, and droughts), which can contribute to food shortages, and loss of livelihoods. Globally, irrigated agriculture is one of the key strategies for stabilising food production, protecting farmers from production losses, and enabling all-year-round farming. However, the low use of irrigation and overdependent on rain-fed agriculture in Africa partly explain the continent's low agricultural productivity. Moreover, the lack of clear and effective water rights systems has created a major problem for the management of irrigation water. For example, in South Africa, smallholder irrigation faces problems of low water-use efficiency and cost recovery of government investments [1]. Besides, the water access constraints, energy poverty and limited of access to finance [2] have

$\triangle$ Henry Mensah, hmensah200@yahoo.co.uk|'Department of Environmental Planning, Brandenburg University of Technology, Cottbus-Senftenberg, Germany. ${ }^{2}$ Centre for Settlements Studies, Kwame Nkrumah University of Science and Technology, Kumasi, Ghana. ${ }^{3}$ Department of Planning, Kwame Nkrumah University of Science and Technology, Kumasi, Ghana. 
crippled most irrigation faciliites in Africa. Although irrigation in Africa has the potential to boost agricultural productivity by at least 50 percent, Liangzhi [3] indicates that Africa's irrigated areas are estimated at 13 million hectares, and it is unlikely that more than $1-10 \%$ of the irrigation potential can be implemented in some countries over the next 20 years. Nigeria has the highest potential for both large- and small-scale schemes in Africa [3]. Irrigation contributes immensely to agriculture and has improved economic development efforts particularly in the semiarid and arid regions in the African continent [3]. It continues to have a profound impact on rural development, household incomes, job opportunities, and food security. For example, pump irrigation has improved horticultural production in Western Kenya along a 13-km stretch of the shore of Lake Victoria, providing a substitute to declining fisheries and economic opportunity for young people in the area [4].

In Ghana, despite the factors that affect the performance of irrigated agriculture [5-8] (e.g. faulty design of irrigation schemes, lack of maintenance of the irrigation schemes, limited financial capital for operation and maintenance of irrigation infrastructure, irrigation service fees conflicts, and inadequate coordination among institutions), it contributes significantly to food security, employment, and income $[9,10]$. Ghana's irrigation is classified into informal (smallholder) irrigation, formal irrigation, and large-scale commercial irrigation. Informal irrigation is a practice in which individuals cultivate a small parcel of land with simple farming inputs [7]. In the past, low capital investment has led farmers to use buckets or watering cans for manual irrigation. In recent years, farmers have adopted motorised water pumping machines and other complex technologies that require high initial capital investments. Also, large-scale commercial irrigation is characterised by high-powered pumps, the existence of out-growers, and can be established as joint ventures between the government of Ghana and private companies. Formerly, the formal irrigation schemes were owned and financed by the government of Ghana; however, it failed to operate effectively due to high operation and maintenance cost. This led to the implementation of participatory irrigation management (PIM) strategy in the 1990s. PIM strategy suggests that local users of irrigation resources, if empowered as a group to participate actively in the management of water resources, have the incentive to manage it more efficiently and sustainably than a wholly centrally financed government agency [8] cited in (Vermillion 1997).

To address the challenges in the irrigation sub-sector and increase adaptation to climate change, the government of Ghana has implemented policies to promote new technology to improve irrigated agriculture [9]. Moreover,
Sect. 5.4 of the National Irrigation Policy, Strategies and Regulatory Measures requires stakeholder collaboration, ensuring collaboration among the Ghana Irrigation Development Authority (GIDA), Ministry of Food and Agriculture (MoFA), Water Resource Commission (WRC), Environmental Protection Agency (EPA), private sector entities, government agencies, local governments, and NGOs [9]. Their collective performance is expected to enhance irrigation support services to farmers in terms of providing production credit, technical assistance, rehabilitating and reconstructing irrigation systems, and offering extension services to improve the irrigation systems.

Notwithstanding, the irrigation stakeholder collaboration and role in the irrigation management in Ghana are being questioned by scholars [8] in that, apart from their useful roles, stakeholders have not been fulfilling their collaborative role to enhancing irrigation support services to farmers. For example, Nyadzi et al. [10] revealed that the existing hydro-climatic information systems in Northern Ghana follow a top-down approach where scientists and other technical personnel are the drivers and farmers are the end-users in the irrigated rice farming. The authors further revealed that little or no attention was given to farmers' involvement and participation in the decision-making and knowledge creation process was overlooked. Meanwhile, the irrigation policy in Ghana is socially constructed; therefore, its practical implementation will depend on stakeholders. The collaboration is necessary, and this could work effectively if it is well-managed [11, 12]. Further, effective stakeholder collaboration also encourages goodwill, trust, commitment, communication, and information exchange [13]. Faure [14] points out the need to reinforce farmers' associations at different levels after examining the nature of collaboration between farmer organisations or cooperatives and relevant stakeholders. She further argues that the alliances would justify planned investments, to negotiate financial and technical resources at the national level. Stakeholder collaboration attracts funding [15], as others have highlighted the need to collaborate $[16,17]$ to improve the cost-effectiveness of the intended project. From the foregoing, the research will contribute to the literature on the nature of stakeholder collaboration in managing irrigation schemes. When stakeholder collaboration is strengthened, it will, in turn, enhance support services and strengthen irrigation farmers' resilience to changing climate conditions, particularly in the peri-urban areas. It is evident that Ghana agriculture is vulnerable to climate change [18-20] due to over-reliance on rainfall, and this has resulted in low agricultural productivity, food shortages, and livelihoods insecurity. Moreover, in achieving the sustainable development goals (SDGs) through food security, ending poverty, and promoting sustainable agriculture, the ability of stakeholders to improve irrigation management needs to be strengthened. Irrigation plays a 
pivotal role in the climate change era; however, since irrigation management involves complex relationships among stakeholders, it will depend on the ability of stakeholders to improve the irrigation management, and development. It is therefore important to explore stakeholders' perceptions of collaborative practices in managing the Weija Irrigation Scheme (WIS) of Ghana to inform decision-makers about the existing gaps and way forward.

\subsection{An integrative framework for collaborative governance}

Collaborative governance is widely used in literature. It is a governance arrangement where one or more public agencies directly engage non-state stakeholders in a collective decision-making process that is formal, consensus-oriented, and deliberative, with the aim of making or implementing public policy or managing public programmes or assets [21]. Emerson, Nabatchi, and Balogh [22] define collaborative governance as "the processes and structures of public policy decision-making, and management that engage people constructively across the boundaries of public agencies, levels of government, and/or the public, private, and civic spheres to carry out a public purpose that could not otherwise be accomplished" (p.2). Several studies have also linked collaborative process to resource management outcomes, such as the irrigation service fees payments, operation and maintenance [23], collective action and managed ecosystems [24] and stakeholder conflicts, and community development projects [25]. If a collaborative dynamic is evaluated in the context of irrigation management in Ghana, the results may provide useful insights for decision-makers. The integrative framework for collaborative governance (IFCG) is depicted as a series of interrelated and nested dimensions representing the surrounding system context, the collaborative governance regime (CGR), collaboration dynamics, and actions (see [21]). The IFCG was used in this study to understand stakeholder collaboration in the irrigation sector and identify gaps and way forwards. The most appropriate way to apply this framework is to consider the relevant variables to the local context [22]. In this way, we explore the dimension of the theoretical framework [22] specifically, the dynamics of collaboration which consist of three interactive components: (1) principled engagement; (2) shared motivation; and (3) capacity for joint action, to assess the nature and effectiveness of stakeholder collaration in the management of the WIS, and to determine the factors that inhibit collaboration (Table 1).

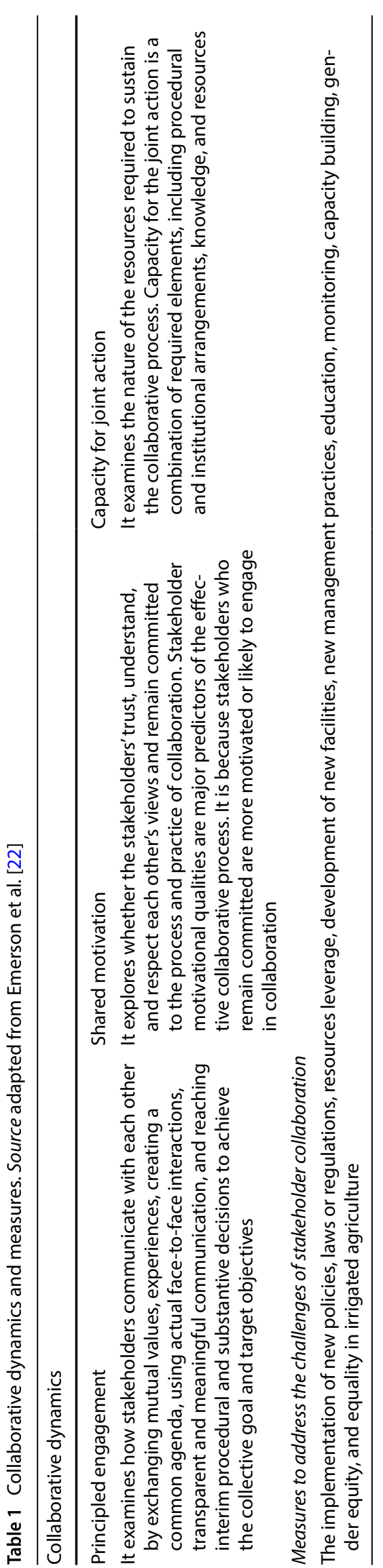




\section{Methodology}

\subsection{Study area}

Weija is the municipal capital of Weija-Gbawe Municipality, located in the south-western part of Accra, Ghana, West Africa (Fig. 1). The WIS is formal irrigation, lake-pumpingbased, and sprinkler irrigation system. It is located in the peri-urban area and was designed to supply water to irrigation farmers in a designated irrigation land. Farmers typically grow vegetables, cassava, okra, and maize. The WIS was chosen for the study because of the following reasons: it is one of the rehabilitated schemes in Ghana; largest producer of vegetable crops in the Greater Accra region; the most expensive sprinkler irrigation scheme in the country due to the two pumping stations; there was limited information on the nature of stakeholder collaboration and practices, although it is one of the formal schemes which receives substantial support from development partners.

\subsection{Study design and approach}

The case study approach was used to explore stakeholders' perceptions about collaborative practices in the management of the WIS of Ghana to inform decision-makers about the emerging gaps and way forward [26]. The approach provides an in-depth insight into a complex social phenomenon as it allows investigators to retain the holistic and meaningful characteristics of reallife events, typically, in organisational, and managerial processes [27]. In examining a single case like this study, other similar cases will benefit from its recommendations. The research aims at farmer organisations, government institutions, agencies, departments, NGOs, development partners, and those responsible for the integral development of irrigated agriculture. The stakeholders

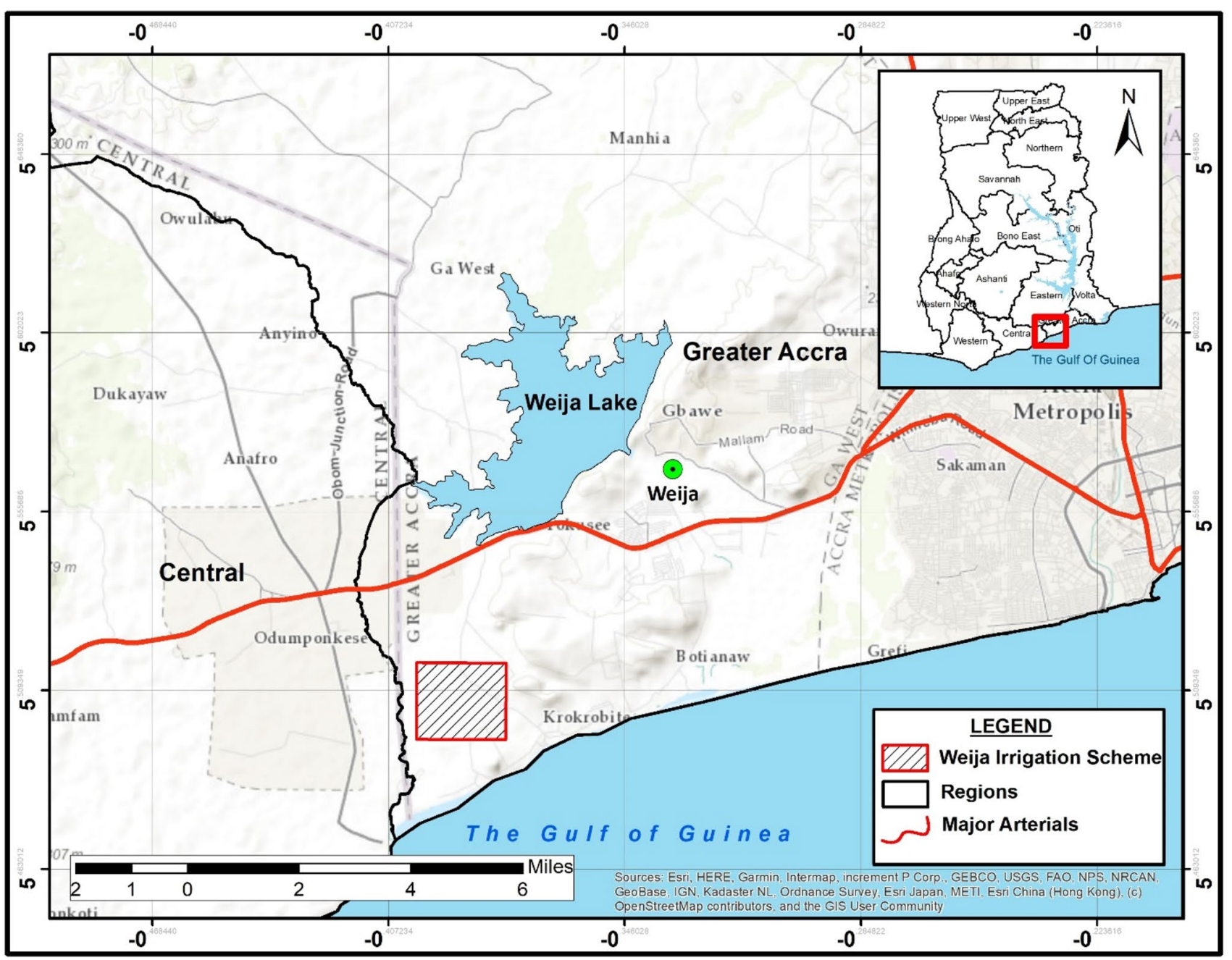

Fig. 1 Location of the study area. Source Authors' construct 
Table 2 List of sample guiding questions used in the study

\begin{tabular}{ll}
\hline Collaborative dynamics & Experts Key informants \\
\hline Principled engagement & How does your organisation functions relate to irrigation management? \\
& How is your relationship with GIDA or stakeholders in the management of the WIS? If no relationship, explain why? \\
& What are the factors that impede and promote collaborative practices among stakeholders in managing WIS? \\
& What are the consequences of ineffective collaboration on WIS management? \\
Shared motivation & What is the extent of motivation for the collaborative practices among stakeholders in managing WIS? \\
& What are the factors that impede and promote collaborative practices among stakeholders in managing WIS? \\
Capacity for joint action are the consequences of ineffective collaboration on WIS management? & What capacity have been developed towards collaboration in managing WIS? \\
& What are the factors that impede and promote collaborative practices among stakeholders in managing WIS? \\
& What are the consequences of ineffective collaboration on WIS management?
\end{tabular}

were studied and analysed within the context of collaborative dynamics, which provides a complete overview and a lens for the discussion. The term "stakeholder(s)" is used in this study to mean government institutions, farmers' organisations, international organisations with a "stake" in irrigation, and are either involved or influenced by it.

\subsection{Sources of data and methods for their collection}

The study relied on secondary and primary data sources. In terms of the secondary data sources, internet-based databases such as Google Scholar and Scopus, were used to gather peer-reviewed articles. The study also relied on organisational reports from GIDA, MoFA, FAO, Japan International Cooperation Agency (JICA), Korea International
Cooperation Agency (KOIKA), EPA, Ghana, Weija municipality, and Farmer Water User Association (FWUA). The primary data collection was based on interviews with key informants, as indicated in Table 3, Agricultural Extension Agents, and heads of farmer groups, as indicated in Table 4, with guiding questions. This study explores stakeholders' perceptions of collaborative practices in irrigation management by identifying gaps and providing suggestions to enhance stakeholder collaboration. In order to achieve the aim, guiding questions were addressed. The primary aim of these questions was to identify and understand the perceptions of relevant stakeholders of collaboration in irrigation management. These questions will offer insight into the way collaborative dynamics facilitate and impede collaboration in the irrigation sector of Ghana. Furthermore, answering these questions facilitated the assessment of
Table 3 List of interviewees and their affiliation. Source Developed by the authors

\begin{tabular}{|c|c|c|}
\hline Stakeholders & Levels & $\begin{array}{l}\text { Number of key } \\
\text { informants inter- } \\
\text { viewed }\end{array}$ \\
\hline \multicolumn{3}{|l|}{ Key stakeholders } \\
\hline Ghana Irrigation Development Authority (GIDA) & National & 3 officials \\
\hline Ghana Irrigation Development Authority (GIDA) & Local & 3 officials \\
\hline Agricultural department/Ministry of Food and Agriculture (MoFA) & Local & 3 officials \\
\hline Environmental Protection Agency (EPA) & Local & 3 officials \\
\hline Ghana Water Company Limited (GWCL) & National & 1 official \\
\hline Weija Municipal Assembly (WMA) (Central administration) & Local & 2 officials \\
\hline Environmental and Sanitation Department (under WMA) & Local & 2 officials \\
\hline Physical Planning Department (under WMA) & Local & 2 officials \\
\hline Development Planning Unit (under WMA) & Local & 2 officials \\
\hline Traditional Authority (TA) & Local & 2 leaders \\
\hline \multicolumn{3}{|l|}{ Primary stakeholders } \\
\hline Farmers association & Local & 3 officials \\
\hline \multicolumn{3}{|l|}{ Secondary stakeholders } \\
\hline Japan International Cooperation Agency (JICA) & National & 2 experts \\
\hline Food and Agriculture Organisation (FAO) & National & 3 officials \\
\hline Korean International Cooperation Agency (KOICA) & National & 1 expert \\
\hline Total & & 32 \\
\hline
\end{tabular}


Table 4 List of participants in the focus group discussion. Source Developed by the authors

\begin{tabular}{ll}
\hline Groups & $\begin{array}{l}\text { Number of } \\
\text { partici- } \\
\text { pants }\end{array}$ \\
\hline Group 1: Scheme management committee members & \\
Scheme manager & 1 \\
Scheme engineer & 1 \\
Extension agent & 2 \\
FWUA chairman & 1 \\
FWUA vice-chairman & 1 \\
Secretary & 1 \\
Treasure & 1 \\
Member & 1 \\
Total & 9 \\
Group 2: Farmers' groups & \\
Farmers group 1 & 1 leader \\
& 1 taskforce \\
Farmers group 2 & 1 leader \\
Farmers group 3 & 1 taskforce \\
Farmers group 4 & 1 leader \\
Total & 1 taskforce \\
\hline
\end{tabular}

the effectiveness of collaboration in the irrigated agricultural sub-sector. Table 2 sets out guiding questions that were used for the collection of primary data.

In this study, we classify the irrigation stakeholders into three categories: (1) Key stakeholders include stakeholders that can significantly influence or are important to the success of the irrigation scheme. (2) Primary stakeholders (beneficiaries) are affected either positively or negatively by the outcome of the irrigation scheme. (3) The secondary stakeholders have a marginal effect on the result of the irrigation scheme (Table 3). The stakeholders or institutions were selected based on the key role they play in irrigation management in Ghana. In addition, the key informants were purposefully selected based on their interest, experience, and the key role they play in irrigation agriculture in Ghana. In total, 32 people were selected and interviewed: 1 was female, and 31 were males. Interview appointments were made with the key informants through a telephone call to confirm the date and time of the interview. Prior to any interview, there was an in-depth background check of each organisation through their website. Open-ended questions (not different from the interview guide) were also administered to two government officials who could not meet the interview schedule time and were encouraged to answer the questions based on their own experience.

\section{SN Applied Sciences}

The FGDs were conducted in August 2017. The FGD sessions were recorded on a digital voice recorder while notes were taken in a field notebook. The participants in group 1 comprised scheme management committee members (some of whom are part of the FWUA) in the WIS, namely Scheme Managers, Scheme Engineers, Agricultural Extension Agent, FWUA Chariman, Vice Chariman, Secretary, Treasurer and a member. The participants in group 2 were farmers. They included leaders of farmers group 1, group 2 , group 3, and group 4 and the taskforce under each group of the WIS (Table 4). Focus groups lasted for approximately $80 \mathrm{~min}$. An advantage of the focus group discussion is that it provides interaction between participants and highlights their views, and experiences [28]. After the FGD, the findings were presented to participants for validation.

\subsection{Sampling}

The participants were selected using a purposive sampling technique [29]. It allows the identification of specific individuals who have an answer to the research questions. Purposive sampling was complemented by the snowball sampling method [30]. This means, we used a small group of initial key informants to choose other key informants who have answers to the research questions during the snowball sampling method. The reason is that there was no clear-cut access to the stakeholders due to the fragmented nature of the institutions.

\subsection{Data analyses}

The study applied a content analysis technique to identify emerging issues from the interview's transcripts to have meaning with the research questions [31]. The transcribed data from the focus group discussions and interviews were analysed by an empirical method of qualitative content analysis. The transcribed data were coded and analysed using NVIVO 10. NVIVO 10 is professional software that allows researchers to achieve more reliable coding in the shortest possible time and identify patterns of ideas during compiling, disassembling, and reassembling. Figure 2 shows the process of identifying themes from interview transcripts. The transcribed data was grouped into three main topics consistent with the study questions.

\section{Results}

Figure 3 presents the summary of stakeholders' roles, collaboration challenges, and their effects on WIS. 
Fig. 2 Process of identifying themes from interview transcripts. Source: Developed by the authors

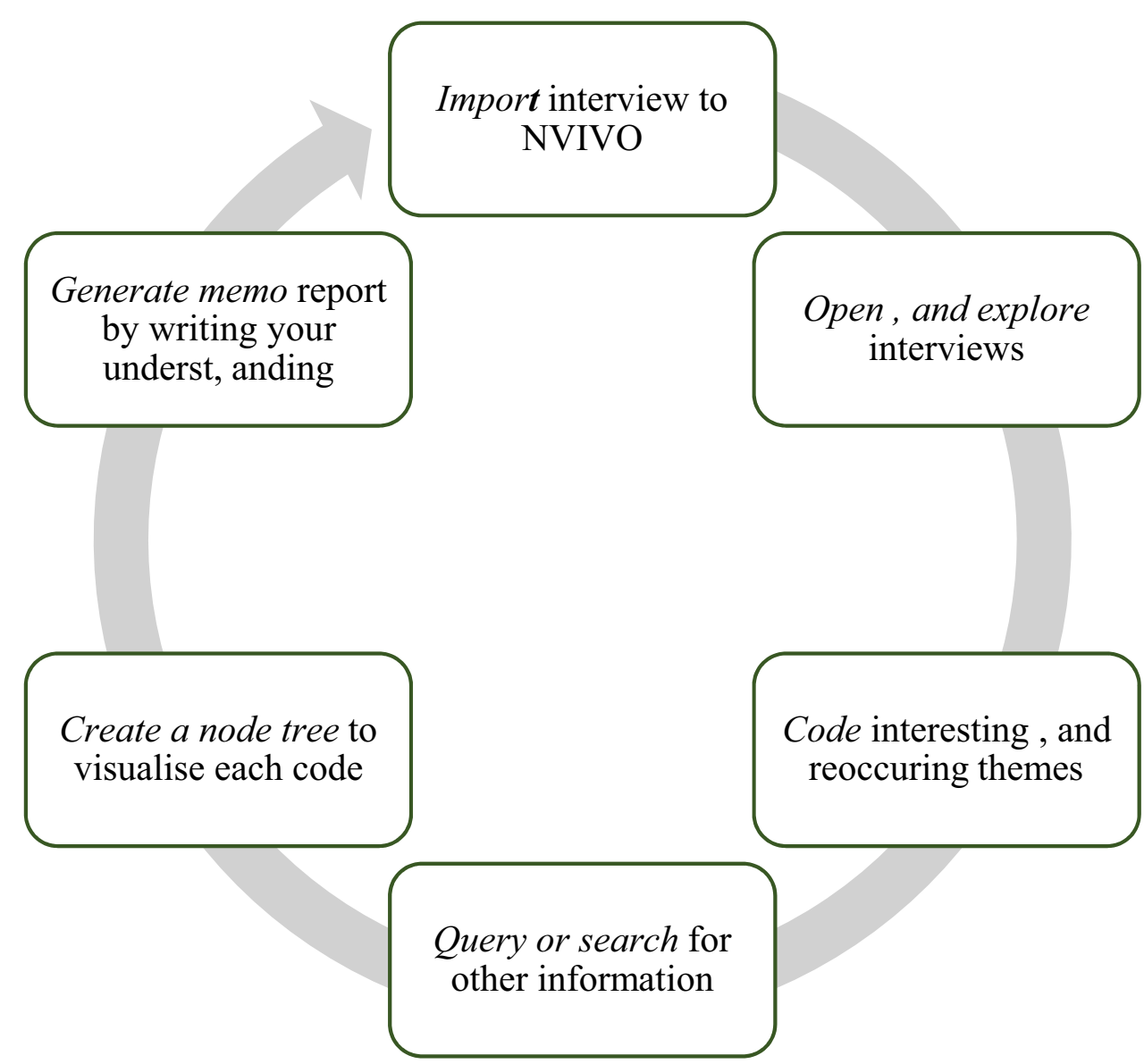

\subsection{Principled engagement}

Weak communication among stakeholders emerged as the topmost challenge of effective collaboration for the management of the WIS. Communication and exchange of information were mentioned repeatedly as compared to the other barriers in the transcribed data. The study indicated that some stakeholders found it difficult to access vital information from each other. This has contributed to the lack of awareness among departmental heads and decision-makers of development projects and activities of other stakeholders, and in turn, had led to duplication of work. It was recorded that the self-interest of some stakeholders created conflicts and miscommunication of information among the stakeholders. According to the scheme manager:

The problem of irrigation land encroachment is worrying and this has been compounded by the lack of communication with the responsible stakeholder that will assist farmers in addressing the problem. This has led to the continuous encroachment of irrigation land by livestock and residential land uses. The conflicts among the stakeholders should be resolved quickly in order to hasten the development process of the WIS.

The study revealed that GIDA collaborated with FWUA for conflict management, irrigation operation, and maintenance. Collaborative practice is initiated before, during, and after each irrigation project. Before any irrigation project proposal is prepared, the idea is discussed at the ministerial level (MoFA), followed by visibility studies of the intended project in consultation with FWUA. Meetings are usually organised for the management team (i.e. scheme management committee members and leaders of farmers' groups and task forces) to enhance their technical capacity and knowledge in the operation and maintenance of the planned project. These measures have allowed the exchange of information and knowledge. On the contrary, it emerged that the farmers lacked leadership skills that could support growth of the irrigation sector through innovation for sustainable agriculture. More so, conflict sometimes arose among irrigation farmers due to differing personal interests or goals. For example, it was mentioned by the scheme manager that despite local by-laws of preventing livestock from grazing in the irrigation farmland, livestock are often seen on the irrigation 


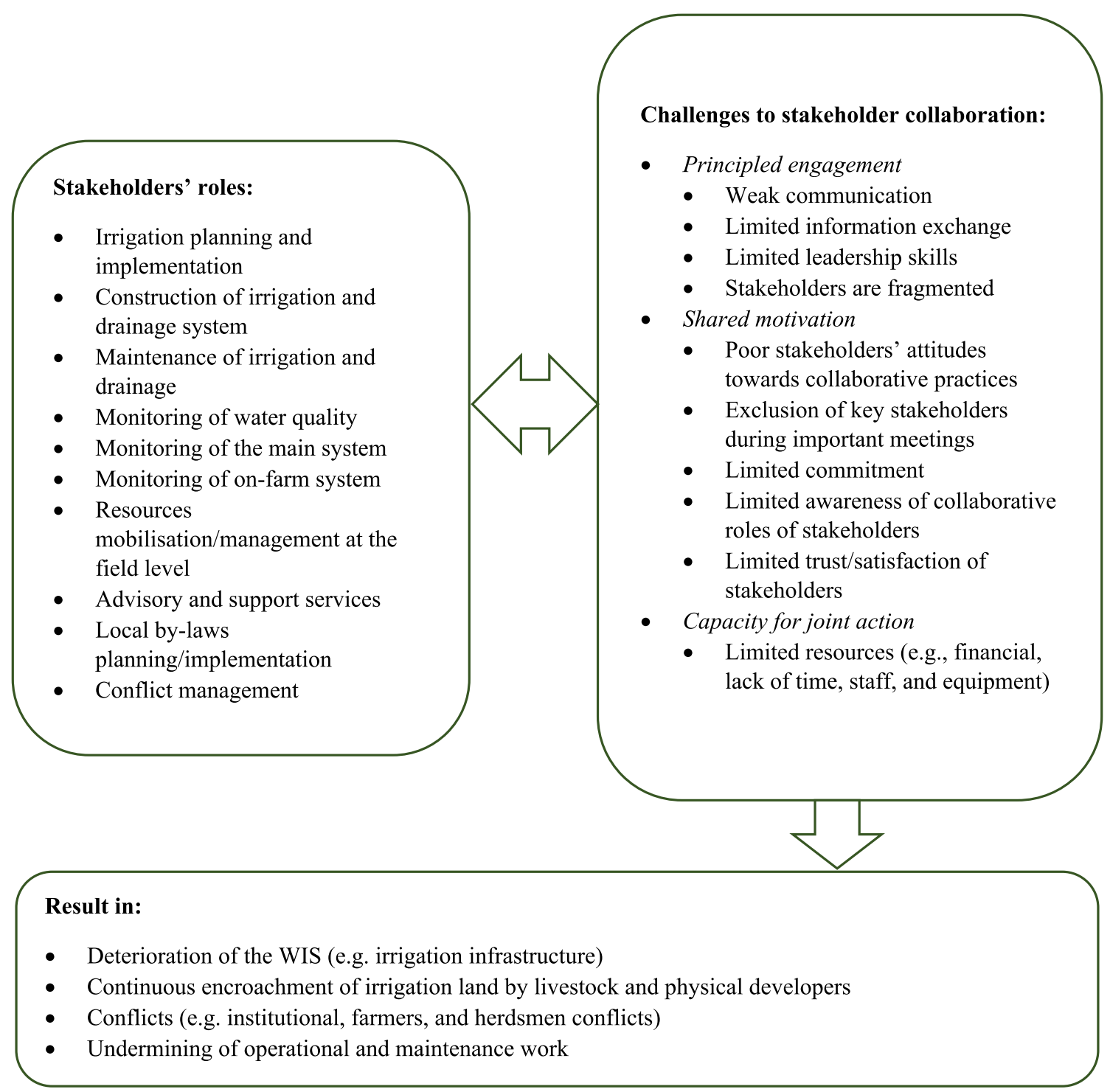

Fig. 3 List of themes according to stakeholders' roles, challenges to stakeholder collaboration, and their effect. Source: Developed by the authors, based on the results of this study

farmland, destroying crops, which results in interpersonal conflict. GIDA organised forums for farmers to present their problems and allowed them to engage with authorities. However, it was pointed out that difficulties in engaging farmers regularly have led to several disagreements, propagating mistrust, and dissatisfaction with the irrigation management.

The TA plays an advisory role, provides support services, and implements local regulations to ensure the security of the WIS. It was observed that the irrigation communities are required to collaborate with GIDA to avoid misunderstanding, particularly issues related to land ownership and encroachment. According to the representatives of GIDA, GDA is expected to create awareness at the community level. Thus, farmers, community members, traditional rulers (e.g. the chiefs, queen mothers, and opinion leaders) are well informed about any planned projects. It was noted that the continuous encroachment of irrigation land by livestock, and physical developers have undermined the potential of WIS. Community mobilisation has become difficult, and TA power to enforce the local by-laws and regulations is weakened due to the lack of respect for the traditional culture. Consequently, such individual behaviours have become unbearable and have contributed to the loss of social capital. 


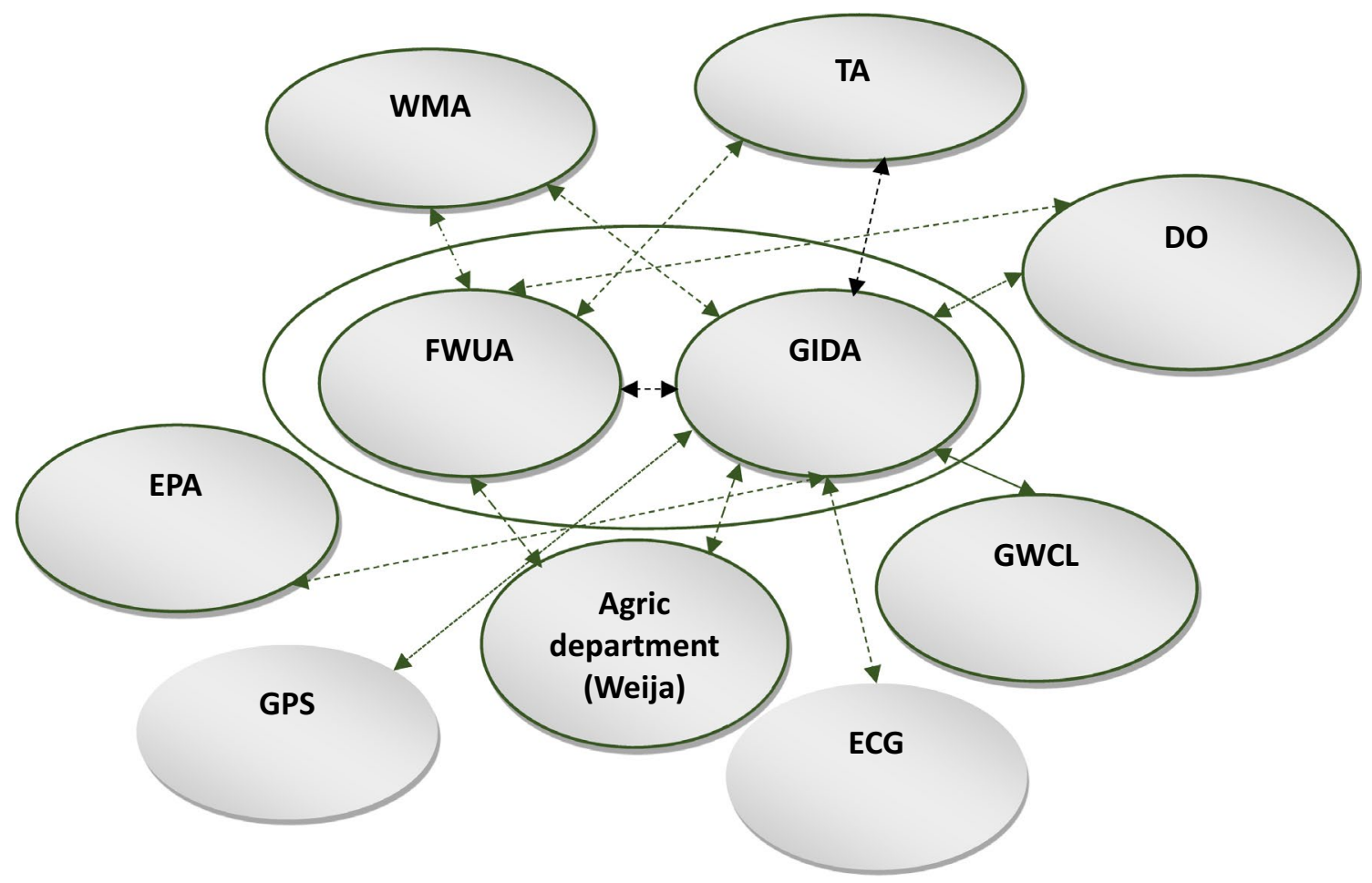

The extent of linkages

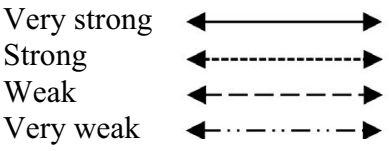

Fig. 4 Illustration of stakeholders' extent of linkages. Source: Developed by the author, based on the results of this study

\subsubsection{The existing relationships among key stakeholders in the irrigation management}

Figure 4 shows the existing relationships among the stakeholders and outlines the strengths and opportunities for developing meaningful strategies and linkages.

3.1.1.1 GIDA and stakeholders' relationships In the irrigation management of Ghana, there are implementing units, collaborating agencies, and partners that collaborate with GIDA in different ways. For instance, GIDA and Ghana Water Company Limited (GWCL) share water resource; therefore, both need to share frequent information. It emerged that GIDA has weak linkage with other stakeholders, particularly with the MWA and Electricity Company of Ghana Limited (ECG), which prevented them from negotiating on some crucial matters, such as "subsidising electricity charges" for FWUA. GIDA is expected to enhance the relationship with other stakeholders through capacity building. This is because some stakeholders were reluctant to invest in irrigation due to the high cost. Moreover, GIDA introduced a participatory management approach where FWUA would support maintenance of irrigation infrastructure. However, the implementation of the participatory management appraoch has been plagued with several setbacks. GIDA maintained that it is open for collaboration with any stakeholder, but highlighted that its key goal was to enhance the overall performance of the WIS. GIDA recognised the important roles of Ghana Police Service (GPS) and ECG for the prevention of land encroachment and in the reduction of electricity charges for FWUA, respectively, to enhance the performance of WIS. According to GIDA official that:

It was difficult to change the mindset of some stakeholders, but it calls for immediate education and sensitisation programmes, such as refresher courses or training support to change their attitudes towards collaboration. When there is no collaboration, development practitioners tend to duplicate the work that 
has already been done leading to unnecessary con-

flicts among stakeholders and farmers.

\subsubsection{FWUA and stakeholders' relationships During the} farming season, weak linkages were recorded among FWUA, the Department of Agriculture, and WMA. However, within FWUA, farmers exhibited mutual relationship, which has allowed easy equipment, information, and knowledge sharing. Although FWUA plays an important role in irrigation management, its linkage with other implementing agencies is weak. Leaders of the farmers' groups maintained that FWUA should be periodically consulted on matters that relate to irrigation as failure to do so would adversely affect their livelihoods. The FWUA felt that farmers could contribute positively to the development process, and also ensure positive collaboration in the future. Additionally, stakeholders make some commitments to the relationship, but are reluctant to make too specific commitments. For example, the management did not relay FWUA concerns to the top authorities. Moreover, decisions are made at the irrigation head office without farmers' inputs, and authorities do not often visit the WIS. The FWUA perceived some stakeholders as unreliable, and the weak linkage or engagement hindered the progress of the WIS. Ideally, irrigation systems function properly when FWUA and other stakeholders work together. A leading member of FWUA remarked that:

During meeting with government officials, we present our concerns, and they write them down. We wait patiently for their feedback, but nothing will come. We do not trust them anymore, and some do not attend meetings when other organisations call for a meeting and promise them to address farmers' problems. This problem has been going on for a long time. We are not happy about it.

3.1.1.3 MWA and stakeholders' relationships It emerged that officials of the WMA, Environmental and Sanitation Department (under WMA), Physical Planning Department (under WMA), Development Planning Unit (under WMA) had limited time to engage with other stakeholders due to work overloads. During project feasibility studies, GIDA shares information with WMA to make the officials aware of the agricultural situation in the municipality. The study showed that the relationship between the WMA and the stakeholders was very weak. The funding that could have been used to facilitate stakeholder engagement was abysmally limited. This has portrayed the WMA as non-committed to irrigation management. One assemblyman expressed concern that the irrigation was not at the heart of the local government:
During general assembly meetings or town hall meetings, what do they plan, how do they plan, in their meetings what development do they do, what kind of development do they talk about, do they talk about irrigation with other stakeholders, or it is because the irrigation is a farm activity, so it is only the farmers' responsibility?

Agricultural activities are reported to the Department of Agriculture of the WMA. The Department prepares and submits reports to the Municipal Planning Coordinating Unit of WMA; however, an official of the Department of Agriculture (Weija) commented that:

I would like to stress that the relationship between the Department of Agriculture and the GIDA representative at the local level is formal and there is no real collaboration. I have a limited report from the irrigation scheme, so if there are problems with irrigation, I'm not going to know as well as the WMA. It is therefore in the interest of irrigation officials to provide the Department of Agriculture with the information that is required regularly.

3.1.1.4 TA and GIDA relationships In recent times, WIS is beset with many challenges; key among them is land encroachment. The study found a weak linkage between TA and GIDA in resolving the problem. It was found that the traditional leaders sold land that is earmarked for irrigation farming to property developers. Moreover, to build a consensus among stakeholders on land issues, it is was critical to include TA to have an equal voice in decisionmaking. It also emerged that continuous encroachment of irrigation land by stray animals and property developers has led the GIDA to strengthen its capacity to safeguard the WIS for the future. To address some of the problems, the local government ordered livestock farmers to build cages to confine their livestock. This order was introduced due to the frequent conflict between farmers and cattle owners. It was also revealed that a good relationship existed between TA and stakeholders, particularly the chief during project delivery. Moreover, the study found minimum community commitment and involvement in terms of problem identification and planning of irrigation development projects. The traditional authorities indicated that their full participation in decision-making in planning and implementation of local projects would enhance their goodwill towards future projects in the WIS.

3.1.1.5 DO and stakeholders' relationships The DO maintained a culture of hard work and support to their irrigation partners. For example, FAO engaged effectively, both formal and informal manner, with project staff in the project delivery. These staff included Scheme Man- 
ager, Agricultural Extension Agents and Engineers for relevant information, and in return offered feedback. However, currently, the engagement with FWUA has not been active due to communication barriers. For example, due to limited communication among stakeholders, partners are unable to meet the required output of the irrigation schemes. The FAO representative maintained that they are willing to support future collaboration and development as needed. Talking about this issue, FAO representative responded that:

We work with our partners, and it depends on the need. For example, we collaborate with WIS and FWUA because they have canal problems that they want to solve. However, if there is another need, for instance, concerning crops, we do not involve GIDA but the Crops Directorate under MoFA. When it comes to livestock, we deal with the Animal Production Directorate. FAO works through the Government of Ghana, and the government has Ministries, Departments and Agencies with which we work.

\subsection{Shared motivation}

Stakeholders have acknowledged that commitment is important in any relationship building. Moreover, irrigation projects are planned by GIDA who identifies and partners with relevant stakeholders. However, it was reported that some stakeholders are less committed to teaming up for project monitoring. For example, some stakeholders did not give information on time, which undermines the delivery of project time. This has slowed down operation and maintenance work. It emerged that commitment to project partners build trust, and the best results are achieved. The chairman of FWUA mentioned that:

Some stakeholders promised farmers with inputs at subsidised prices, they will provide market for our produce and the likes. You will sign a memorandum of understanding with the person/organisation. The organisation goes to the scheme site and is not able to carry out its duty as outlined in the memorandum of understanding. So it becomes a challenge meanwhile you have signed the memorandum with GIDA on behalf of framers. So even though private companies play a major role in the development of agriculture, they are committed only to what benefits they would derive.

The study revealed that some of the stakeholders, particularly the WMA, are completely unaware of the condition of the WIS. This was because some stakeholders were not invited to meetings. For example, many of the initiatives undertaken in the WIS comprised a small number of key stakeholders. Other relevant stakeholders who could have made significant inputs for the betterment of the WIS were ignored. WIS management required an interdisciplinary approach to address social and environmental problems facing the sector. However, the exclusion of other relevant stakeholders makes the existing team less interdisciplinary. An official at the Environmental and Sanitation department said that:

We are supposed to visit the irrigation site to inspect the canal, whether they are choked or not, whether they have the potential of breeding mosquitoes. Our departments have not been there before, when the canals are choked, it can breed mosquitoes and bite farmers, and it can cause malaria. The issue is not budget, but when they organise meetings and supposing the meeting participants are ten, they invite only five, and that is why we are left behind. But if the decision-makers understand our relevance to the irrigation, I think they will invite us.

It emerged that stakeholders have a lukewarm attitude, which affected the collaborative practice. For example, between GIDA and FWUA, there was a guideline for the operation and maintenance of the irrigation scheme, and each had a defined role to play. However, it emerged that the parties were not performing their collective role as required. Some farmers in the FWUA have lukewarm attitudes towards irrigation operation and maintenance. This is due to the unproductive past projects, which have generated mistrust, and prevented farmers from taking part in the farm meetings. Examples of such projects included abandoned solar dryer and greenhouse infrastructural project, intended to support farmers in the WIS. The FWUA attributed this problem to the central government and stakeholders' inaction to support the WIS. The scheme manager narrated that:

When you are writing a proposal for funding, the collaborative strategies will be indicated on paper perfectly. For example, we will work with this and that institution, this is the lead organisation, and the other organisations will follow. For the planning, there is no problem because most of the time we get the fund from the donors and they will expect to see these strategies. However, when it comes to the implementation of that collaboration strategies which is indicated in the project proposal, it become a problem.

The DO provides financial or technical assistance to GIDA/MoFA and supports the construction of the irrigation scheme and drainage system. They also support the government in formulating and implementing policies, designing and contributing to irrigation scheme 
programme content. At this level, there was a Memorandum of Understanding (MoU) describing each party's role. The DO collaborated with GIDA and farmers in the workshops to address irrigation problems and suggest the way forward. It emerged that the collaboration between them lies in mutual benefits. DO provided technical experts to GIDA, and in return, received baseline information from GIDA before project implementation, although this could vary from organisation to organisation. It was reported that some project partners could not fulfil their mandate as required, and frequent feedbacks were continuously delayed. Also, some stakeholders typically assumed that it is the sole responsibility of the government and DO to support farmers. Thus, this has overburdened the DO and government in supporting the irrigation sector.

\subsection{Capacity for joint action}

The study revealed that financial constraints pose a key barrier to collaboration. It was mentioned that GIDA faced financial difficulties in operating and maintaining the irrigation scheme. Due to limited funding, GIDA and other stakeholders are unable to organise workshops, seminars, forums, and other forms of capacity building activities for stakeholders. GIDA mentioned that financial barriers included lack of funds for transport and supplies, which prevents the staff from motivating other stakeholders to participate in collaborative practices. The majority of representatives from the DO indicated that the main problem associated with stakeholder collaboration was lack of time (e.g. scheduling of meetings). For MWA, inadequate resources were in the forms of time, staff, funds, and equipment which prevent them from supporting the WIS. Generally, the District Assembly Common Fund, which could have been used to support the WIS, is limited. An Agricultural Extenson Agent remarked that:

We do not have enough resources to build the capacity of farmers. Once upon a time, there was a disease on the plant so I had to go and talk to the farmers. Due to resource constraints, I had to walk to the farmgate. With something like this you need to buy fuel for the motor and at time if you go and request for money, it will not come, so if you are government worker, extension, and you have to go and engage with farmers every day, that means you have to use your own pocket money and sometimes if you don't have money, it means you cannot go to the field.

In Ghana, GIDA is responsible for the management and regulatory functions of irrigation infrastructure. In practice, GIDA requires close collaboration with MoFA in the irrigation planning, implementation, monitoring and construction of new irrigation schemes or rehabilitation of existing schemes. This is due to the massive capital investment in the construction of the irrigation infrastructure, which GIDA cannot handle alone. For example, it emerged that MoFA oversees agricultural development in Ghana; therefore, it has the legitimate power to agree to any financial support to GIDA in the development of irrigation projects. GIDA submits an annual report to MoFA, which contains the development constraints and the way forward of various irrigation schemes in Ghana. Both parties are required to communicate and exchange information to gain knowledge during collaborative meetings, workshops, and forums to unearth new challenges that have plagued the irrigation sector. However, it was revealed that these arrangements are not regularly performed due to limited finance, which undermines regular training programmes for stakeholders.

In Ghana, local government institutions have a defining role to play in local administration and development. For the successful implementation of the irrigation policy, local authorities were required to collaborate with GIDA and FWUA in advisory roles, support services, and implementation of local by-laws. The local authorities are required to monitor all development activities and provide an advisory role and support service-planning, community development, and environmental management. However, it was reported that these arrangements have not occurred due to limited funding. GIDA's inability to support collaborative practices has led to the exclusion of major stakeholders in the local government. The government institutions exist to serve the people; however, the newly transferred government staff or departmental heads in the WMA are not effectively integrated into the municipal development. It was recorded that the newly appointed heads, due to limited collaborative skills and training, focus less on stakeholder engagement, which matters for the municipality.

\section{Discussion of the results}

The study highlights the stakeholders' perception of collaboration through the tripartite prism of "principled engagement, shared motivation, and capacity for joint action". In the scope of the study, the principled engagement, shared motivation, and capacity for joint action have been found to be important to achieve effective action [22]. In the light of principle engagement, this study revealed that the relationships among some key stakeholders, such as FWUA, TA, and WMA was weak, and this has resulted in deterioration of the WIS. Communication and sharing of information sharing remain weak. In terms of shared motivation, there were minimal commitment to joint project, exclusion of some key stakeholders from 
meetings, and negative attitudes towards collaboration. Finally, capacity for joint action is limited. The reason is that there were inadequate resources (e.g., lack of funds, time, staff, and equipment) to organise meetings and facilitate and maintain relationship building.

Addressing the obstacles facing irrigation management and building a common vision are essential for an effective stakeholder collaboration. Therefore, the findings suggest rich opportunity for solution to deal with these challenges to inform the implementation of irrigation projects in Ghana and beyond. Generally, in managing irrigated agriculture, the decentralised bodies play various roles [32]; however, the results of this research suggest that few departments in the WMA are contributing to the management of the irrigation scheme. Stakeholders were not willing to commit to initiating and participating in meetings or forums as well as providing useful information to other stakeholders [24]. It was also revealed that although NGOs were required to collaborate, their interest in irrigation was minimal. GIDA supports irrigation schemes through development projects but was crippled by limited funding. Meanwhile, irrigation projects are capital intensive, which require substantial capital outlay, and labour support to execute effectively. The success of collaborative activities depends largely on the interaction between principled engagement, shared motivation, and joint action. This implies increasing irrigation funding for GIDA to assist farmers to improve their farming activities. Cline and Collins [33] demonstrate that stakeholders increase collective action by pooling and exchanging their resources.

Irrigation planning and implementation might not be successful without addressing the needs of FWUA. Quickly, strategic policies are required to strengthen stakeholder collaboration in all irrigation schemes. Another important aspect is that following irrigation technical feasibility studies and stakeholders' consultation processes, GIDA could create community awareness involving all relevant stakeholders. The limited communication between FWUA and stakeholders undermines access to critical information during the farming season. The solution will require a good relationship with traditional rulers, such as chiefs, queen mothers, and opinion leaders in the community [17]. Similarly, the presence of local leaders in irrigation projects is relevant because they express their concerns and acceptability of the proposed project [34].

In governance, the local government system is particularly important. In the WIS, GIDA was required to collaborate with the WMA so that they are aware of the state of irrigation farming in the municipality. Additionally, in terms of negotiation for funds, GIDA must inform local leaders and relevant stakeholders. However, the current study indicates that effective collaboration has been undermined by inadequate communication, inadequate funding, and limited information sharing. This is similar to the findings of Faysse et al. [35], who indicate the lack of interaction, limited funding, and staff were some of the key factors that inhibited agricultural activities. Current collaboration practices require that institutions such as state agencies, government departments, or organisations function together to achieve a common goal. Since stakeholders were required to play supporting and advisory roles in the management of WIS, some key stakeholders were left out during meetings, thus preventing them from accessing important information. For example, in other studies, it was reported that stakeholders were more likely to be proactive and collaborative if they were aware of the problems [36, 37]. In terms of funding irrigation projects, GIDA could increase their lobbying capacity with local and international funding organisations. This will help to ensure the availability of infrastructural funds to run operation and maintenance [38].

The current stakeholders' relationships suggest that stakeholders lacked an understanding of their collective roles. Some of the stakeholders have weak linkages. Generally, it was observed that meetings of the stakeholders were on ad hoc basis. These ad hoc meetings are unplanned and instructed, thus disturbing the activities of farmers [39]. This implies the clarification of stakeholders' roles at the beginning of project planning to promote synergies [40]. Moreover, land encroachment and animal grazing on irrigation land were not acceptable. This problem persists but could have been addressed if there were frequent interaction and exchange of information among the FWUA, WMA, TA, GIDA, and GPS. Furthermore, the important roles of GPS and ECG in terms of preventing land encroachment, and negotiating electricity tariffs to enhance the performance of WIS should not be overemphasised in the WIS context.

The decentralisation policy of Ghana suggests that local government bodies collaborate effectively with MoFA and GIDA, and ensures that government policies and programmes are appropriately carried out at local level [41]. The reason is that they view agriculture as the sole responsibility of the agriculture department or GIDA/ MoFA. This has led to irrigation issues not being holistically tackled. GIDA should strive to enhance collaboration of stakeholders and this has implications for the revision of the legislation that establishes GIDA. Emerson et al.'s. framework [22] has shown that principled engagement, shared motivation, and capacity for joint action necessary for effective collaborative practice are less practised in the WIS of Ghana. Therefore, WIS could benefit from the configuration of principled engagement, shared motivation, and capacity for joint action to engage all stakeholders in collaborative problem-solving. 


\section{Limitation}

This study explores stakeholders' perceptions on collaborative practices in the irrigation management by identifying gaps and providing suggestions to enhance stakeholder collaboration. This qualitative study focuses on the experiences of key informants at the management level in the WIS of Ghana. The study findings are not generalisable to all irrigation professionals in Ghana considering the methodological approach of the study.

\section{Conclusion and recommendations}

The overarching aim of this study explores stakeholders' perceptions on collaborative practices in the irrigation management by identifying gaps and providing suggestions to enhance stakeholder collaboration. The results indicate that despite government desire to ensure effective stakeholder collaboration for planning and managing irrigation schemes, stakeholder collaboration for the management of the WIS was weak. It emerged that the relationships among some key stakeholders such as FWUA, TA, and WMA was weak, and this has resulted in deterioration of the WIS. For an effective collaborative in the WIS, inadequate resources to maintain, operate, and rehabilitate irrigation scheme, inadequate commitment to joint project, exclusion of some key stakeholders from irrigated agriculture-related meetings, weak communication and information exchange, and poor stakeholder attitudes towards collaboration efforts need to be addressed. The study recognises the important roles of GPS and ECG in terms of preventing land encroachment and negotiating electricity tariff, respectively, to enhance the performance of WIS. Even though this study is restricted to Ghana, the reflection of the irrigation management issue in the global south makes the result of the present studies useful for the entire region. The study is the first step to understanding stakeholder collaboration in the WIS of Ghana. The ensuing recommendations may enhance the effective stakeholder collaboration:

- Resource leveraging: GIDA should be financially strengthened. The government in consultation with GIDA and DO should support the WIS in improving irrigation infrastructure, improving operation and maintenance and reducing high electricity charges. FWUA should lobby properly with GIDA for funding to carry out their development projects. The assistance may also be derived from partnership initiatives with DO and private sectors.
- Initiating joint project: Improve the relationships and communication through the establishment of municipality stakeholders' panel for lesson sharing and coordination, and to improve communication and information exchange. FWUA, Government agencies and departments, NGOs, DO, private sectors, and consultants may be represented in the municipality stakeholders' panel to discuss irrigation.

- Capacity training: Increase MWA and FWUA capabilities for project planning, implementation, and monitoring. Leadership development and training could be organised for local stakeholders to promote positive stakeholder attitudes and perceptions towards collaborative practices, and also enhance the relationship among stakeholders.

- Behavioural change: The poor attitudes of the WMA towards collaboration and irrigation management need to be changed. All relevant departments in the WMA need to be properly engaged at the beginning stage of the irrigation projects.

- Future research could also focus on factors influencing willingness to participate in stakeholder collaboration by farmers and irrigation authorities in Ghana as well as the effects of dysfunctional stakeholder collaboration on the performance of other irrigation management areas.

Acknowledgements We wish to express our profound gratitude to the anonymous reviewers for their constructive criticisms and suggestions.

Authors' contributions HM contributed to the study conception and design. Material preparation, data collection and analysis were performed by HM, DJN, OA, and SAT. The first draft of the manuscript was written by DJN and HM, and OA and SAT reviewed the draft manuscript. All authors read and approved the final manuscript.

\section{Declarations}

Conflict of interest The authors declare that they have no conflict of interest.

Open Access This article is licensed under a Creative Commons Attribution 4.0 International License, which permits use, sharing, adaptation, distribution and reproduction in any medium or format, as long as you give appropriate credit to the original author(s) and the source, provide a link to the Creative Commons licence, and indicate if changes were made. The images or other third party material in this article are included in the article's Creative Commons licence, unless indicated otherwise in a credit line to the material. If material is not included in the article's Creative Commons licence and your intended use is not permitted by statutory regulation or exceeds the permitted use, you will need to obtain permission directly from the copyright holder. To view a copy of this licence, visit http://creativecommons. org/licenses/by/4.0/. 


\section{References}

1. Speelman S, D'Haese M, Buysse J, D'Haese L (2008) A measure for the efficiency of water use and its determinants, a case study of small-scale irrigation schemes in North-West Province, South Africa. Agric Syst 98:31-39. https://doi.org/10.1016/j.agsy.2008. 03.006

2. Mashnik D, Jacobus $H$, Barghouth $A$ et al (2017) Increasing productivity through irrigation: problems and solutions implemented in Africa and Asia. Sustain Energy Technol Assess 22:220-227. https://doi.org/10.1016/j.seta.2017.02.005

3. You L, Ringler C, Wood-Sichra U et al (2011) What is the irrigation potential for Africa? A combined biophysical and socioeconomic approach. Food Policy 36:770-782. https://doi.org/10.1016/j. foodpol.2011.09.001

4. Bosma L (2015) 'You've got to pump it up': Analysis of the appropriation and utilization of petrol pumps for small scale horticulture in West-Uyoma, Kenya. University, the Netherlands. MSc thesis, Wageningen

5. Poussin J-C, Renaudin L, Adogoba D et al (2015) Performance of small reservoir irrigated schemes in the Upper Volta basin: case studies in Burkina Faso and Ghana. Water Resour Rural Dev 6:50-65. https://doi.org/10.1016/j.wrr.2015.05.001

6. Mendes MD. Paglietti L, Jackson D (2014) Ghana: Irrigation market brief: FAO Investment Centre. FAO and IFC, Rome, Italy

7. Namara RE, Horowitz L, Nyamadi B, Barry B (2011). Irrigation development in Ghana: past experiences, emerging opportunities, and future directions. In: GSSP Working Paper 27. International Food Policy Research Institute, Washington, DC

8. Braimah I, King RS, Sulemana DM (2014) Community-based participatory irrigation management at local government level in Ghana. Commonw J Local Gov. https://doi.org/10.5130/cjlg.v0i0. 4067

9. MoFA (2011) National irrigation policy, strategies and measures. Ghana Irrigation Development Authority (GIDA), Accra, Ghana

10. Nyadzi $E$, Nyamekye AB, Werners SE et al (2018) Diagnosing the potential of hydro-climatic information services to support rice farming in northern Ghana. NJAS Wageningen J Life Sci 86-87:51-63. https://doi.org/10.1016/j.njas.2018.07.002

11. Mensah H, Ibrahim B (2018) Perceptions of male and female in collaborative process at Weija irrigation scheme of Ghana. J Adv Agric Technol 5:159-165. https://doi.org/10.18178/joaat.5. 2.159-165

12. Ricart Casadevall S (2016) Improving the management of water multi-functionality through stakeholder involvement in decision-making processes. Util Policy 43:71-81. https://doi.org/10. 1016/j.jup.2016.04.015

13. van Rooyen AF, Ramshaw P, Moyo M et al (2017) Theory and application of agricultural innovation platforms for improved irrigation scheme management in Southern Africa. Int J Water Resour Dev. https://doi.org/10.1080/07900627.2017.1321530

14. Faure G (2004) Characterization of a collective action between farmers' organizations and institutions in an innovative process to face liberalization in Costa Rica. J Agric Educ Ext 10:121-131. https://doi.org/10.1080/13892240485300191

15. Bremer LL, Auerbach DA, Goldstein JH et al (2016) One size does not fit all: natural infrastructure investments within the Latin American water funds partnership. Ecosyst Serv 17:217-236. https://doi.org/10.1016/j.ecoser.2015.12.006

16. Nhundu K, Mushunje A, Aghdasi F (2015) Nature and role of water institutions-implications to irrigation water management in Zimbabwe. Irrig Drain Sustain Strateg Syst. https://doi. org/10.5772/59056
17. Anokye NA (2013) Stakeholder Participation in Water Resources Management: The Case of Densu Basin in Ghana. Vrije Universiteit Amsterdam

18. Okyere $E$ (2016) Effect of climate change and variability on cocoa output in the Western Region of Ghana. pp. 1-127

19. Kemausuor F, Dwamena E, Bart-plange A, Kyei-baffour N (2011) Farmers' perception of climate change in the Ejura-Sekyedumase District of Ghana. J Agric Biol Sci 6:26-38

20. Limantol AM, Keith BE, Azabre BA, Lennartz B (2016) Farmers' perception and adaptation practice to climate variability and change: a case study of the Vea catchment in Ghana. Springerplus 5:830. https://doi.org/10.1186/s40064-016-2433-9

21. Ansell C, Gash A (2007) Collaborative governance in theory and practice. J Public Adm Res Theory 18:543-571. https://doi.org/ 10.1093/jopart/mum032

22. Emerson K, Nabatchi T, Balogh S (2012) An integrative framework for collaborative governance. J Public Adm Res Theory 22:1-29. https://doi.org/10.1093/jopart/mur011

23. Hanatani $A$, Fuse $K$ (2012) Linking resource users' perceptions and collective action in commons management-an examination of water supply systems in Southern Senegal. Water Policy 14:127-147. https://doi.org/10.2166/wp.2011.031

24. Woldesenbet WG (2018) Collaborative governance: assessing the problem of weak cross-sectoral collaborations for the governance of Addis Ababa Rivers. Appl Water Sci 8:116. https://doi. org/10.1007/s13201-018-0763-1

25. Gyan C, Ampomah AO (2016) Effects of stakeholder conflicts on community development projects in Kenyase. SAGE Open 6:215824401663525. https://doi.org/10.1177/2158244016 635254

26. Ritchie J, Spencer L (2010) Qualitative data analysis for applied policy research. Analyzing qualitative data. Taylor \& Francis, Abingdon, pp 173-194

27. Yin RK (2003) Case study methodology R.K. Yin (2003, 3rd edition). Case Study Research design and methods. In: Case Study Research: design and methods. Sage, Thousand Oaks (CA), pp 19-39; 96-106

28. Powell RA, Single HM, Powell RA (1996) Focus groups is a focus group? Int J Qual Heal Care 8:499-504

29. Tongco MDC (2007) Purposive sampling as a tool for informant selection. Ethnobot Res Appl 5:147-158. https://doi.org/https:// doi.org/10.17348/era.5.0.147-158

30. Atkinson R, Flint J (2001) Accessing hidden and hard-to-reach populations: snowball research strategies. Soc Res Updat 33:1-4

31. Hsieh HF, Shannon SE (2005) Three approaches to qualitative content analysis. Qual Health Res 15:1277-1288. https://doi.org/ $10.1177 / 1049732305276687$

32. Nagrah A, Chaudhry AM, Giordano M (2016) Collective action in decentralized irrigation systems: evidence from Pakistan. World Dev 84:282-298. https://doi.org/10.1016/j.worlddev.2016.02. 003

33. Cline SA, Collins AR (2003) Watershed associations in West Virginia: their impact on environmental protection. J Environ Manage 67:373-383. https://doi.org/10.1016/S0301-4797(02) 00222-0

34. Frederick KD (2016) Managing water for economic, environmental, and human health. Global Development and the Environment. Routledge, Routledge, pp 69-78

35. Faysse N, Sellika IE, Rinaudo JD, Errahj M (2018) Participatory scenario planning for sustainable irrigated agriculture when actors seldom communicate: an experiment in Morocco. Int $J$ Water Resour Dev 34:982-1000. https://doi.org/10.1080/07900 627.2017.1322500

36. Aarts HFM, Humphreys J, Le Gall A (2014) Effective stakeholder communication in agriculture: together we stand, divided we fall! J Agric Sci 152(S1):65-70 
37. Neef A, Neubert D (2011) Stakeholder participation in agricultural research projects: a conceptual framework for reflection and decision-making. Agric Human Values 28:179-194. https:// doi.org/10.1007/s10460-010-9272-z

38. Swamy DRR (2019) Financing aspects of sustainable water management in India. In: Water Governance: challenges and prospects. Springer, Singapore, pp 289-302

39. Susskind L, Camacho AE, Schenk T (2012) A critical assessment of collaborative adaptive management in practice. J Appl Ecol 49:47-51. https://doi.org/10.1111/j.1365-2664.2011.02070.x

40. Lambrecht I, Vanlauwe B, Maertens M (2016) Agricultural extension in Eastern Democratic Republic of Congo: does gender matter? Eur Rev Agric Econ 43:841-874. https://doi.org/10.1093/ erae/jbv039

41. MoFA (2007) Food and agriculture sector development policy (FASDEP II). Ministry of Food and Agriculture, Accra, Ghana

Publisher's Note Springer Nature remains neutral with regard to jurisdictional claims in published maps and institutional affiliations. 